\title{
Design and Digital Interactive System for Medicine
}

\author{
Cristina Portugal \\ PUC-Rio \\ Av. Gal Felicíssimo Cardoso 835 b02 \\ 701, Rio de Janeiro - Brazil \\ crisportugal@gmail.com
}

\begin{abstract}
This paper presents a research project of interdisciplinary nature between the fields of Design and Medicine, which was supported by Tender FAPERJ No. 41/2013 - "Support program for Emerging Research Groups in the State of Rio de Janeiro - 2013" and that aimed to technologically develop an interactive digital system to help the surgical team in the operative act for treatment of patients with endometriosis. This paper will present the methodological aspects that guided this investigation, which has a qualitative approach, and the result of this project, which was the creation of an unprecedented digital bilingual interactive system, in light of methods and techniques of Design, to be used in national and international circles both for recording the diagnosis of endometriosis as well as in surgeries.
\end{abstract}

Information design. Data visualisation. Interdisciplinary. Endometriosis.

\section{INTRODUCTION}

This paper presents a research project of interdisciplinary nature between the fields of Design and Medicine, which was contemplated by Tender FAPERJ No. 41/2013 - "Support program for Emerging Research Groups in the State of Rio de Janeiro - 2013" and that aimed to technologically develop an interactive digital system to help the surgical team in the operative act for treatment of patients with endometriosis.

The project was born from the experience of the Gynecology team from "Antônio Pedro Hospital" and from the Maternal and Child Department from Fluminense University Federal with the collaboration of Professor Dr. Cristina Portugal from Department of Arts \& Design of Pontifical Catholic University of Rio de Janeiro (PUC-Rio). Works about this research project received two prizes so far: the work "Diagram to Map the Locations of Endometriosis" won in 2013 the prize for best poster of the ESGE (European Society of Gynecology Endoscopy), in Berlin, Germany; and in 2014 the paper "Infdesign digital system for mapping of endometriosis sites" received the prize of best paper in the subject area of information design in the 11th Brazilian Congress of Research and Development in Design on the city of Gramado, Brazil.
The objective of this research project is to elaborate a digital interactive system developed for the WEB and that may be executed in browsers compatible with W3C standards. The system may operate on-line, storing images on the cloud, or offline, with local storage.

The partnership between Design and Medicine fields, in this case, has the objective of allowing data visualisation in order to communicate information clearly and effectively by means of graphic resources. In other words, creating in digital format the existing analogue model, enabling a visual mapping corresponding, in a practical and objective way, to the areas affected by endometriosis, which are part of the clinical record, and that may be used in the follow-up of patients with the disease.

This paper will present the methodological aspects that guided this investigation, which has a qualitative approach, and the result of this project, which was the creation of an unprecedented digital bilingual interactive system, in light of methods and techniques of Design, to be used in national and international circles both for recording the diagnosis of endometriosis as well as in surgeries, when the system will help to orient the removal of foci of the disease, having the need and concern of specialists to avoid incomplete resections and to carefully evaluate the possibility of multifocality and multi-centrality of the wounds. 


\section{RESEARCH METHODOLOGY}

The methodological aspects which guided this investigation, that had a qualitative approach, are present in the research process for the development of the digital system for mapping endometriosis sites:

- To research, in light of Design methodologies, means for the construction of a digital system for mapping endometriosis sites.

- To develop the information architecture of the digital environment according to characteristics, which are divided in four large interdependent systems, each one composed by its own rules and applications: Organisation System, Navigation System): Labeling System) and Search System.

- To develop the navigational components such as menus, arrows, navigation nodes, hypertext, images.

- To develop a digital map for platforms Windows and IOS - (Project development under the perspective of methodologies from the field of Design).

- To interview selected groups of professionals from the medical field. From observations made about the use of the digital map, results will be analyzed to reinforce, exemplify and found the question of effectiveness in the use of the product (Semi-structured interviews).

- To elaborate a prototype of the digital system

- To validate the digital map with teachers of the medical field.

\section{DATA VISUALISATION IN THE DIGITAL SYSTEM}

Information is essential for performing the medical activity, as well as in the coordination of the actions of the multidisciplinary team and in planning and acquiring the administrative and financial resources needed in every situation. The clinical record must be clear and precise, ease to understand for the team members, in an organised and standard way, giving a meaning for the context in question. The inclusion of a visual diagram representing the places affected by endometriosis may be a guide in the moment of the surgical approach and later clinical follow-up.

The need to transfer all information acquired during the pre-operative of patients with endometriosis for the moment of the operative act is extremely important, because there is a large interval of time between the beginning of the investigation and the operative act. Considering that, in most of the cases, the operative time of patients with endometriosis exceeds five hours of duration, being considered a delicate and high costly procedure, it becomes indispensable that the diagnosis of the disease has been clearly identified so that the surgical procedure, which uses a series of specific instruments and equipments, happens inside a previous planning in order to avoid intercurrences. The fact that the investigation is performed by a different team from the one that will perform the surgical procedure and more, the fact that normally the patient passes through different institutions during this process, requires that its medical records had been properly recorded, because the improvement of the patient is directly correlated with the removal of all endometriosis foci that were identified during the pre-operative.

With the possibility of using a digital interactive system pointing the sites of endometriosis, it will be possible to, still in the ambulatory - moment in which the surgery indication is given -, fill this digital map. The same map will be latter reproduced in the surgery room, recapitulating the information of the pre-operative. This resource may help the surgical team to be aware about the complexity of the surgery, mapping focus of the disease, preventing the oblivion of some site, as well as establishing the probable operative time and inherent risks. Thus, the "digital map" represents the memory of the pre-operative investigation being an important tool in the operative act.

For making the digital map the involvement of professionals from different areas was needed, in an interdisciplinary work, in other words, gynaecologist doctors, designers, programmers and professionals from the computing field.

The first prototype of the application developed in the digital system for mapping endometriosis sites under the light of Information Design is presented as follows. Those lay-outs are not final, but they already show some functionalities that will be available in the interface.

The first image (Figure 1) shows a general overview of the interface. The rectangles with acronyms are buttons with three states, one deactivated and two activated. With a click the user defines a state and, with a second click, changes for the second state. Each state is represented with a different color. The fields in blue at the side of some buttons (BEX, OVA, RET and SIG) are for the input of numeric values. On top of the page there are fields for the record of the patient. 

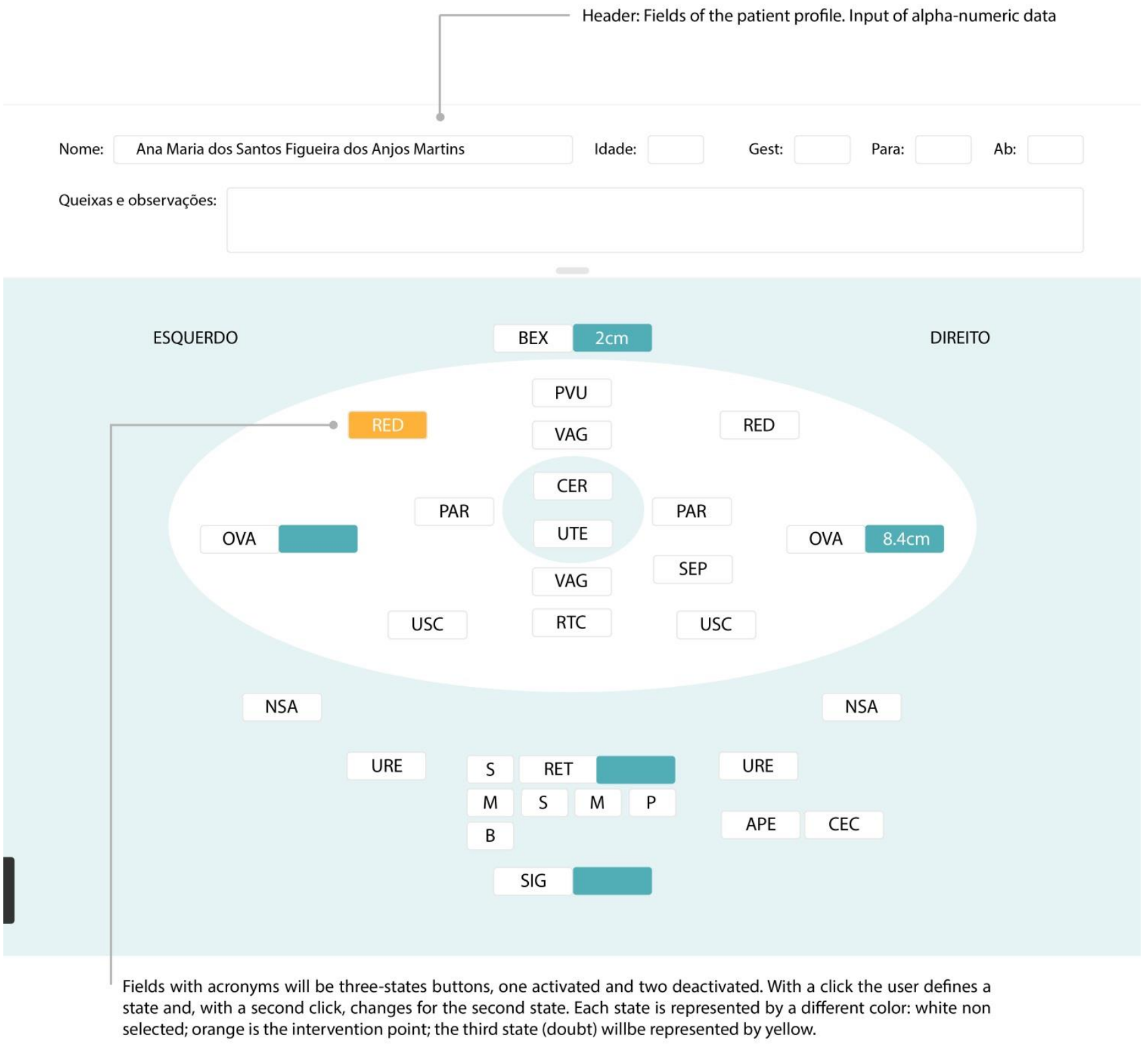

Figure 1: Interface of the digital interactive system for mapping endometriosis sites 
The input of numeric values may be performed in two ways: by conventional typing or by a circular slider (only for the Tablet version). With a click in the field, the normal data input mode is triggered. By clicking and dragging over the field, the data input mode by slider is triggered

Nome: Ana Maria dos Santos Figueira dos Anjos Martins $\quad$ Idade: $\quad$ Gest:
Queixas e observações:

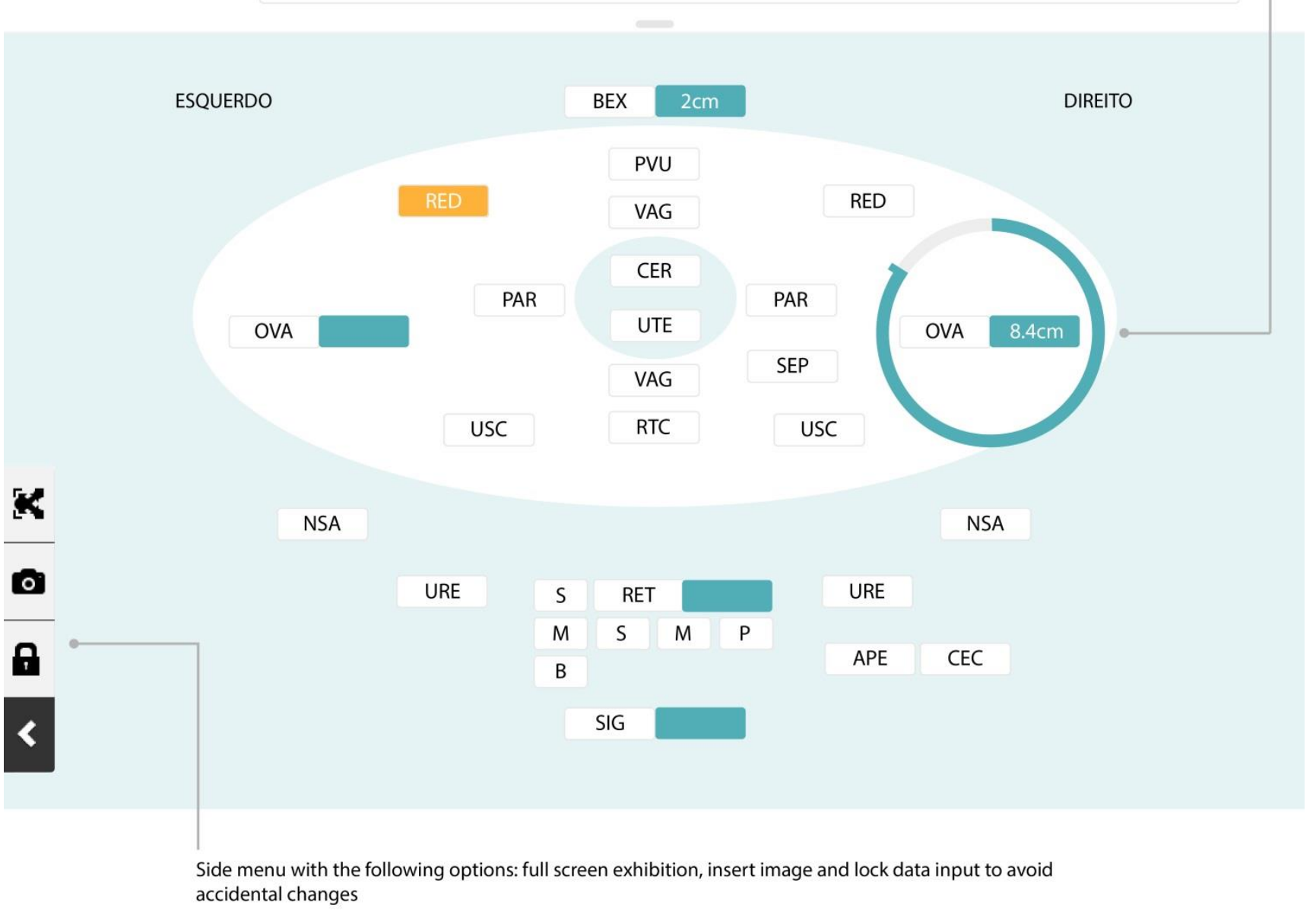

Figure 2: Interface of the digital interactive system for mapping endometriosis sites 


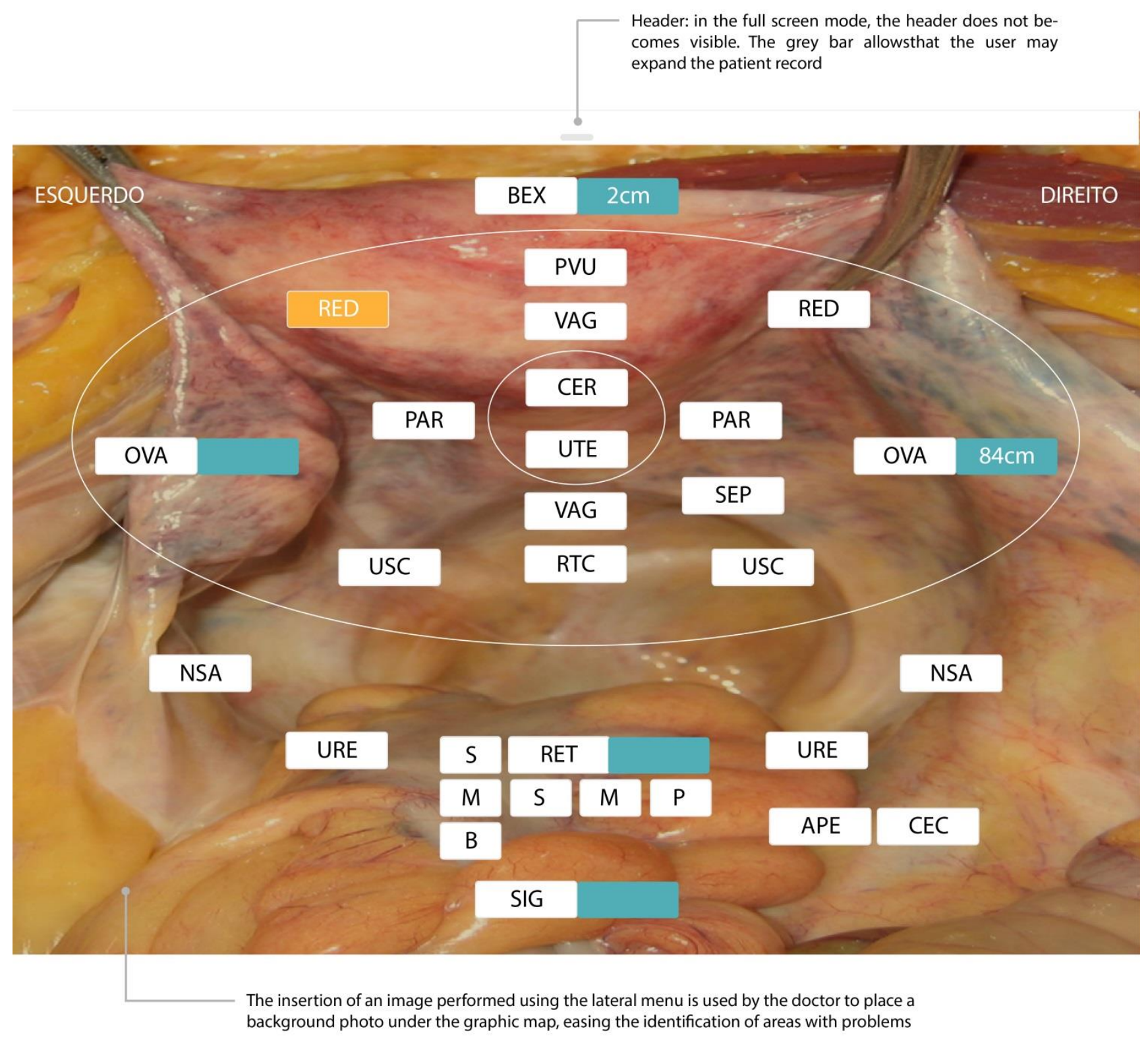

Figure 3: Interface the digital interactive system for mapping endometriosis sites

The input of numerical values may be made in two ways: by conventional typing of by a circular slider (Figure 2). With a click on the field, the data input mode is activated (keyboard). By clicking and dragging over the field, the input mode by slider is activated. The lateral menu allows the following options: display in full screen, insert image and lock data input so that no accidental changes are made.

The insertion of an image of the patient uterus is used by the doctor to put a background image under the graphic map, easing the identification of areas with problems. The image (Figure 3 ) shows an example of a photo applied. As we have no ways of previewing the size of the image that the doctor will insert, it is necessary to allow the resizing of the photo, when necessary.

The application will be developed to run in tablets, but the first version will only run on desktops. For the desktop version we will consider the data input as numbers only, since it is not possible to have a touch device. This is why the interface offers hybrid resources, compatible with both formats.

With the developed prototype, the system is being evaluated by means of an usability test, which is a formal technique that selects some users in order to represent the target group, in this case doctors, teachers and students of medicine, to whom the system is targeted. Those users were designate in 
order to collect data so that, posteriorly, they will be analyzed and the proper corrections or changes will be made in the system so that it reaches a better degree of usability.

\section{CLOSING REMARKS}

Data are typically quantitative and measurable elements, being easily manipulated by computational processes when codified in digital language. That way, we can apply the computational power to create ways of mapping those data, in order to incorporate new interpretative meanings.

The visualisation of complex data in digital environments, in other words, the dynamic visualisation of data is one of the genuinely new cultural forms that became possible due to computing. (...) With computers we may visualise very wide data sets, creating dynamic visualisation, feeding data in real time, basing the graphic representation of data in their mathematical analysis, using several methods, from classical statistics to data prospection, mapping a type of representation into another (images in sounds, sounds in tridimensional spaces, etc.) (Manovich, 2004, p. 149).

In face of what was exposed, this project of interdisciplinary character between the fields of Design and Medicine solves the question of information overload by means of data visualisation in order to communicate information in a clear and objective way. This not only will allow the clinical record of the patient during the operative act, as well as it could be used in the follow-up of patients with the disease.

The result expected from this project is the creation of a bilingual interactive digital system, unprecedented in light of methods and techniques of Information Design, in order to be used in national and international circuits both for recording the diagnosis of endometriosis as well as in surgeries, when the system will help to orient the removal of foci of the disease, considering the need and worry by specialists of avoiding incomplete resections and carefully evaluating the possibility of multifocality and multi centrality of the wounds.

\section{ACKNOWLEDGEMENTS}

Thank you to FAPERJ for financial help and the project team, including Marcelo Pereira, Mariana Corrêa, and Ricardo Lasmar.

\section{REFERENCES}

Bonsiepe, G. (2011) Design, cultura e sociedade. São Paulo: Edgar Blucher.

Bonsiepe, G. (1997) Design do material ao digital. Florianópolis: FIESC/IEL.

Cybis, W., Betrol, A. H., \& Faust, R. (2007) Ergonomia e Usabilidade - Conhecimentos, Métodos e Aplicações. São Paulo: Novatec.

Dias, A. R. et al. (2012) Identidade de marca e simbologia na interface digital. Estudos em Design | Revista (online). Rio de Janeiro: 20(2), 1-17.

Fry, B. (2002) Organic Information Design. Master of Science in Media Arts and Sciences, Massachusetts Institute of Technology.

http://projects.ischool.washington.edu/tabrooks/424 /OrganiclnformationDesign/thes-0522d.pdf (retrieved 10 March 2013).

Hassenzahl, M. (2008) User Experience (UX): Towards an experiential perspective on product quality. Não paginado. http://www.marchassenzahl.de/pdfs/hassenzahl-ihm08.pdf (retrieved 3 June 2012).

Lasmar R. B, et al. (2012) Diagram to map the locations of endometriosis, Int J Gynecol Obstet., 118(1), 42-46, July.

Manovich, L. (2004) Visualização de dados como uma nova abstração e anti-sublime. In: Leão, L. (org.). Derivas: cartografias do ciberespaço. São Paulo: Annablume.

Moura, M. (2004) Hypermedia Design: relationship between culture, language, transdisciplinarity and information. Selected Readings of the Information Design Internacional Conference, Recife, vol. 1, pp. 144-154.

Pereira, M. F. (2012) A ubiquidade computacional como ferramenta de ensino projetual em Design. Rio de Janeiro. Tese de doutorado - Departamento de Artes \& Design, Pontifícia Universidade Católica do Rio de Janeiro.

Portugal, C. (2013) Design, Educação e Tecnologia. Rio de Janeiro: Rio Books.

Shedroff, N. (n.d.) Information interaction Design: a unified field theory of Design.

http://www.nathan.com/thoughts/unified/ (retrieved 15 August. 2012).

Rosenfeld, L. \& Morville, P. (2006) Information Architecture for the Word Wide Web. 3rd edition. Sebastopol, CA: O'Reilly.

Ulbricht, V. R. et al. (2008) Design de hipermídia: proposta metodológica. In: $3^{\circ}$ Conahpa, São Paulo/SP. 3ํㅡㄹ Congresso Nacional de Ambientes Hipermídia para Aprendizagem.

Wurman, R. S. (2005) Ansiedade de informação 2. São Paulo: Cultura. 